\title{
MANUFACTURE OF LONG-LENGTH SEMI-PRODUCTS FROM SINTERED TITANIUM ALLOYS USING FRICTION WELDING
}

\author{
A.E. KAPUSTYAN \\ Zaporozhie National Technical University MESU \\ 64 Zhukovsky Str., 69063, Zaporozhie, Ukraine. E-mail:glotka87@ukr.net
}

\begin{abstract}
Aim of the present stady lies in determination of possibility of application of conventional friction welding for production of quality joints from sintered titanium alloy in manufacture of long-length semi-products. Commercial titanium powder of PT5 grade of Ukrainian manufacture was used as initial material. Billets for rod production were received by powder metallurgy methods and their chemical composition corresponded to commercial purity of VT1-0 grade titanium. Shaping of billets of $12 \mathrm{~mm}$ diameter and $100 \mathrm{~mm}$ length was carried out by pressing. Long-length semi-products were manufactured using friction welding on MF-362 machine. Welding was performed without additional shielding. Weldability of the specimens was evaluated visually, by means of metallographic investigations and mechanical tests. Analysis of macrostructure of welded joints allowed determining absence of defects of metallurgical nature in the weld and thermal-mechanical-affected zone (TMAZ). Average size of pores in TMAZ and weld was smaller then in the base metal, effect of partial and complete «healing» of pores also took place. Micro-X-ray-spectral quality analysis of weld structure showed uniform distribution of main impurity elements. Mechanical tests of examined welded specimens allowed determining that their strength and ductile characteristics are comparable with that of VT1-0 cast titanium. Possibility of realizing the production of semi-products from sintered titanium alloys in production scales was shown. 5 Ref., 2 Tables, 6 Figures.
\end{abstract}

Key words: titanium, powder metallurgy, pressing, sintering, friction welding, semi-product, rod, strength, structure

Necessity of weldability investigation of sintered titanium billets, produced by friction welding [1], was shown earlier.

Aim of the present stady lies in determination of technical possibility of application of conventional friction welding for formation of quality joints from sintered titanium alloy in manufacture of long-length semi-products (rods).

Commercial titanium powder of PT5 grade (TU 14-10-026-98), produced by SEs «State Scientific-Research and Design Institute of Titanium» and «Zaporozhie Metallurgical Pilot-Production Plant», was used as initial material. Billets for rod production were received by powder metallurgy method. Chemical composition of the billets corresponded to commercial purity of VT1-0 grade titanium (GOST 19807-91). Shaping of billets of $12 \mathrm{~mm}$ diameter and $100 \mathrm{~mm}$ length (Figure 1, $a$ ) was carried out by pressing on hydraulic press with $700 \mathrm{MPa}$ force. Sintering was carried out in vacuum chamber SNVE1.3.1/16IZ at $1250 \pm 20{ }^{\circ} \mathrm{C}$ temperature during 3 hours with $13.3 \mathrm{MPa}$ pressure, cooling took place together with furnace. Long-length semiproducts were manufactured using friction welding on MF-362 machine.

Welding was carried out without additional shielding, since it makes no effect on weld metal

(C) A.E. KAPUSTYAN, 2015 structure [2]. Rod semi-products of $12 \mathrm{~mm}$ diameter and 185-190 mm length (Figure 1, b) were produced as a result of welding. Oxidation of metal to $0.5 \mathrm{~mm}$ depth [2] takes place during welding in air, therefore, according to recommendations of work [3], treatment was carried out at turning machine for removal of surface layer being saturated with gas in order to stabilize mechanical properties.

Weldability of specimens was examined visually (by presence and shape of extruded flash), by means of metallographic examinations and mechanical tests. Microstructural investigations were carried out on sections, made in transverse and longitudinal directions of welded billets, using inverted-stage reflection microscope Observer.D1m and electron microscope JSM6360LA, equipped with attachment for perform-

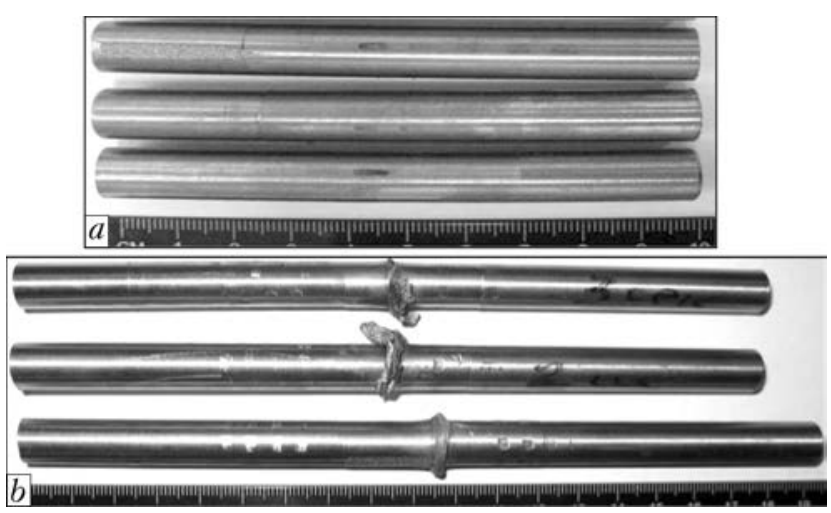

Figure 1. Billets produced based on powder metallurgy method: $a$ - pressed; $b$ - welded (rods) 


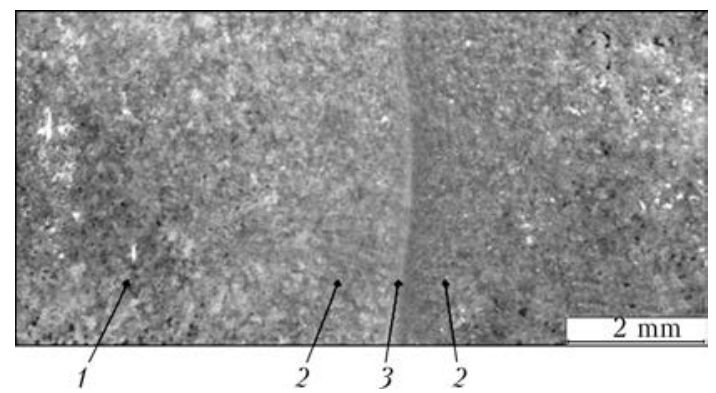

Figure 2. Macrostructure of friction welded joint from sintered titanium VT1-0: 1 - base metal; 2 - near-weld zone 3 - weld

ance of energy-dispersive X-ray microanalysis (XMA). Mechanical tests were carried out on IP-110 machine in accordance with the requirements of GOST 1497-84 using cylinder specimens with $5 \mathrm{~mm}$ diameter test portion.

Visual examination of welded billets showed that extrusion of flash took place all over joint circumference, that indirectly indicates satisfactory weld formation. Each of the billets being joined due to upsetting underwent the similar $5.0-7.5 \mathrm{~mm}$ reduction depending on modes of welding.

Structure was examined on etched sections, manufactured in longitudinal section of welded specimens. Analysis of macrostructure of the welded joints allowed determining presence of thin light weld band of up to $0.3 \mathrm{~mm}$ width along the place of joining of powder billets. A zone, having no clear pores, observed in the base metal of the specimens (Figure 2), is formed in both billets at $2.0-2.5 \mathrm{~mm}$ distance from the weld. No metallurgical defects were found in the weld and thermal-mechanical-affected zone (TMAZ).

Microstructure of pressed billets (base metal of welded specimen) was characterized by presence of disoriented $\alpha$-phase plates, body and boundaries of which included round and sharpcornered pores of up to $70 \mu \mathrm{m}$ size, around $35 \mu \mathrm{m}$ on average (Figure 3, $a$ ).

Examination of welded joint determined ( $\mathrm{Fi}$ gure $3, b$ ) that pores and structural constituents with clearly observed interfaces are virtually absent in weld metal. Microstructure of weld represented itself fragments of $\alpha$-phase grains of up to $5 \mu \mathrm{m}$ size, which were formed as a result of intensive deformation of metal under effect of pressure and friction, at that diameter of found pores does not exceed $3 \mu \mathrm{m}$, that indicated reduction of pores and their possible «healing» under effect of shearing deformation (Figure $3, b$ ).

It should be noted that structure of TMAZ of welded billets had some differences. TMAZ represented itself fine plate-like structure and consisted of radial-oriented $\alpha$-plates of up to $3 \mu \mathrm{m}$ width and up to $150 \mu \mathrm{m}$ length, on interface of which elongated pores of around $15 \mu \mathrm{m}$ were located.
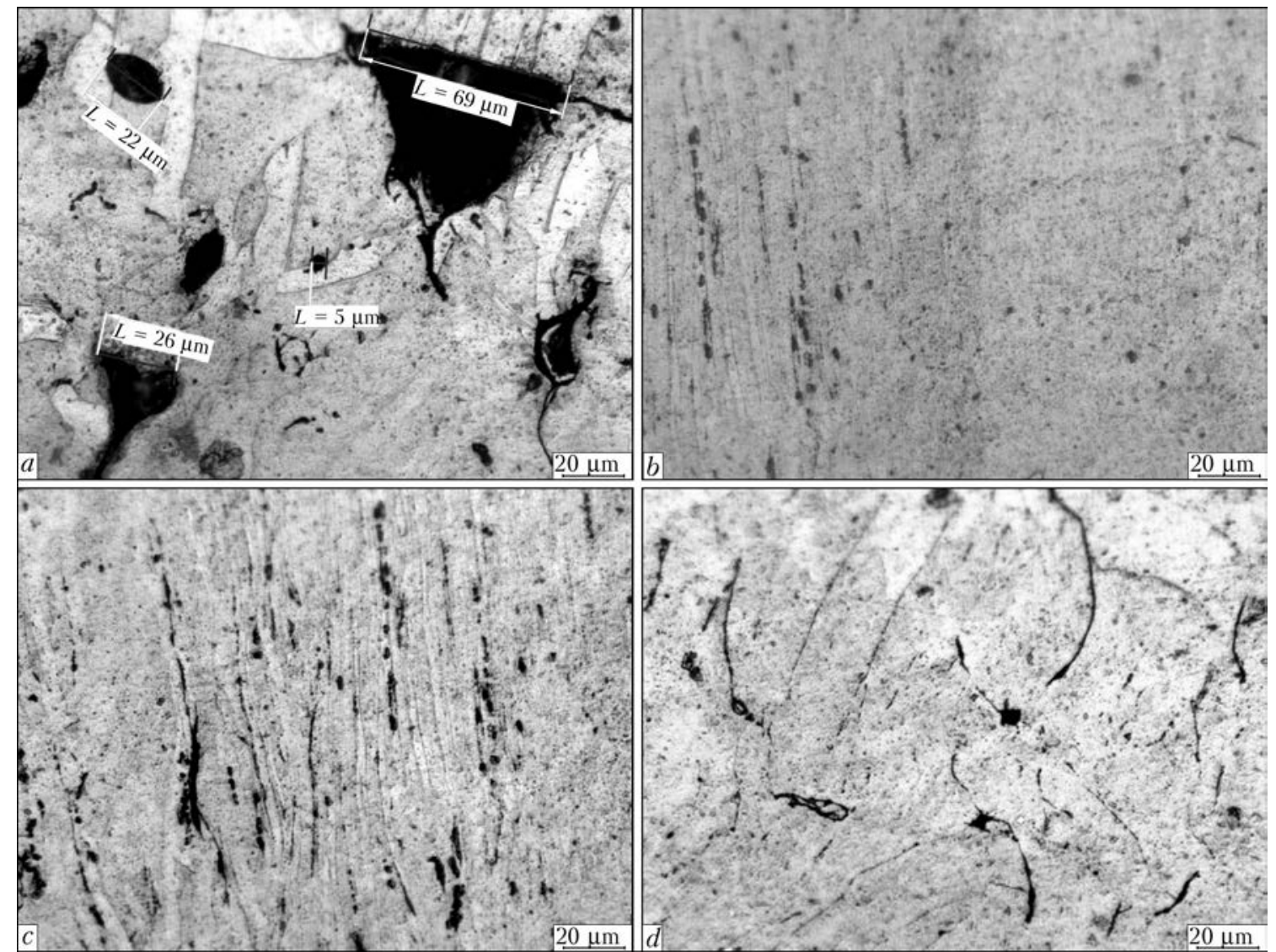

Figure 3. Microstructure of billet from sintered titanium VT1-0 produced by friction welding: $a-$ base metal; $b-$ weld; $c$ - TMAZ located close to weld; $d$ - TMAZ located close to base metal 
Table 1. Amount of some impurities in investigated materials, wt.\%

\begin{tabular}{||l|c|c|c||}
\hline \multicolumn{1}{|c|}{ Material } & $\mathrm{N}$ & $\mathrm{O}$ & $\mathrm{Fe}$ \\
\hline PT5 TU (14-10-026-98) & 0.03 & - & 0.08 \\
\hline $\begin{array}{l}\text { Alloy VT1-0 } \\
\text { (GOST 19807-91) }\end{array}$ & 0.04 & 0.20 & 0.25 \\
\hline
\end{tabular}

Formation of radial orientation and «healing» of pores were promoted by effect of axial force due to upsetting and temperature (Figure 3,c). The same effect is observed in the case of treatment of rods and cast parts from titanium alloys using intensive plastic deformation methods or in gasostat [4].

At the same time, TMAZ located near billet base metal consisted of $\alpha$-phase plates of deformed shape of around $10 \times 50 \mu \mathrm{m}$ size, the pores in this zone had crescent-like shape (Figure 3, d) and were located arbitrarily. Besides single round pores of 4-5 $\mu \mathrm{m}$ diameter were present in its structure.

Thus, the metallographic examination allowed determining that average size of pores in TMAZ metal was smaller than in the base metal as well as partial and complete «healing» of pores took place. Pores were virtually absent in the weld and residual pores were of order smaller then in the base metal.

Micro-X-ray-spectral quality analysis of weld and zones from both sides of the weld showed uniform distribution of main impurity elements (Figure 4). Micro-X-ray-spectral quantity analysis of weld and zones from both sides of the weld (Figure 5) showed that number of main impurity elements does not exceed GOST requirements for VT1-0 alloy (Table 1).

Therefore, non-shielded friction welding of sintered titanium does not result in saturation of weld and TMAZ metal with ambient atmosphere gases.

Mechanical tests of examined welded specimens allowed determining that level of their strength characteristics is comparable with that of cast titanium VT1-0 (Table 2), and lower ductility is promoted by the fact that failure of the specimens takes place in most of the cases out of weld zone, i.e. along the base metal, where larger amount of pores, reducing metal deformation capacity, is observed (Figure 6).

In the whole, values of mechanical properties of weld of sintered VT1-0 titanium billets was at the level of cast titanium properties, and tensile strength of the weld exceeded that of sintered titanium alloy, due to formation of dispersed microstructure with single pores in the weld.

Based on performed investigations, billets of series sizes (40 $\mathrm{mm}$ diameter and $700 \mathrm{~mm}$ length) were produced.

Thus, the possibility is shown for realizing the manufacture of semi-products from sintered titanium alloys in production volumes. This
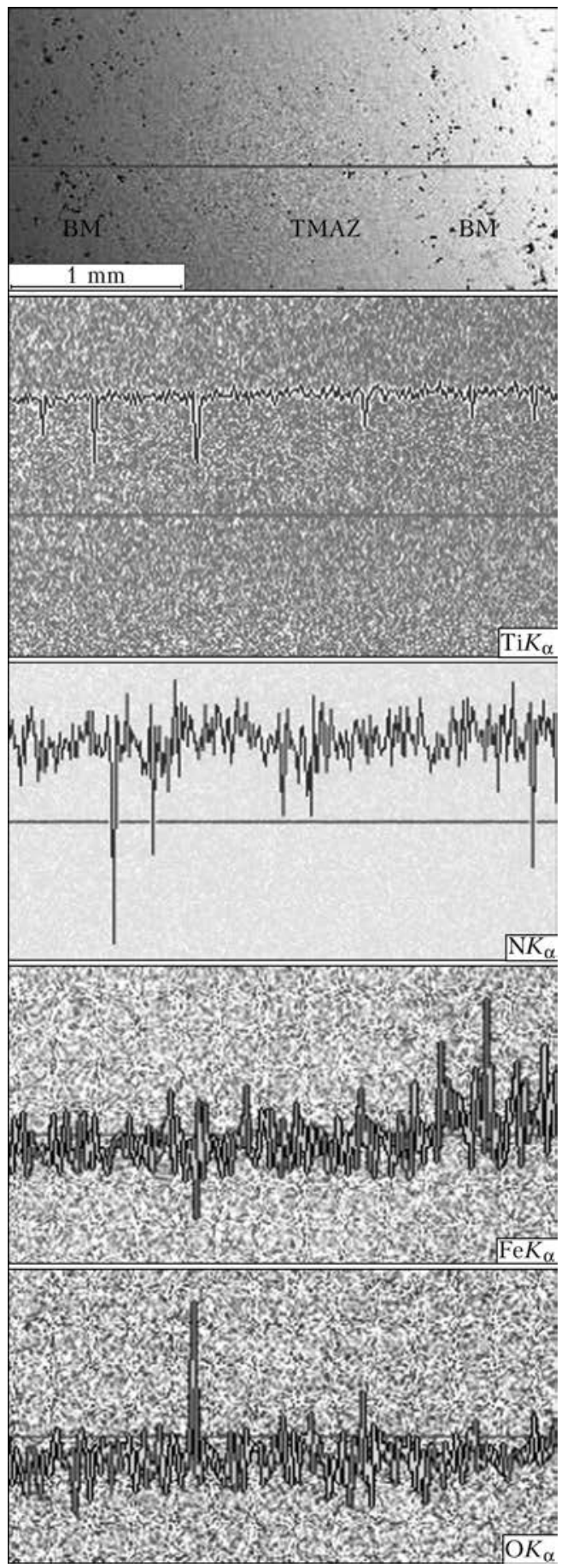

Figure 4. Macrostructure of welded joint from sintered alloy VT1-0 $(a)$, and distribution of elements (Ti, N, Fe, O)

makes a ground for wider application of sintered titanium alloys in form of welded long-length semi-products, providing implementation of titanium in new, large-scale areas of engineering.

Table 2. Mechanical properties of welded billet from VT1-0 titanium alloy produced based on methods of powder metallurgy

\begin{tabular}{||l|c|c|c||}
\hline \multirow{2}{*}{\multicolumn{1}{|c|}{ Material condition }} & \multicolumn{3}{|c||}{ Mechanical properties } \\
\cline { 2 - 4 } & $\sigma_{\mathrm{t}}, \mathrm{MPa}$ & $\delta, \%$ & $\psi, \%$ \\
\hline $\begin{array}{l}\text { Sintered VT1-0 welded billet } \\
\text { (failure out of the weld) }\end{array}$ & $322-338$ & $7-9$ & $14-18$ \\
\hline Cast VT1-0 [5] & $340-390$ & $7-17$ & $33-40$ \\
\hline
\end{tabular}




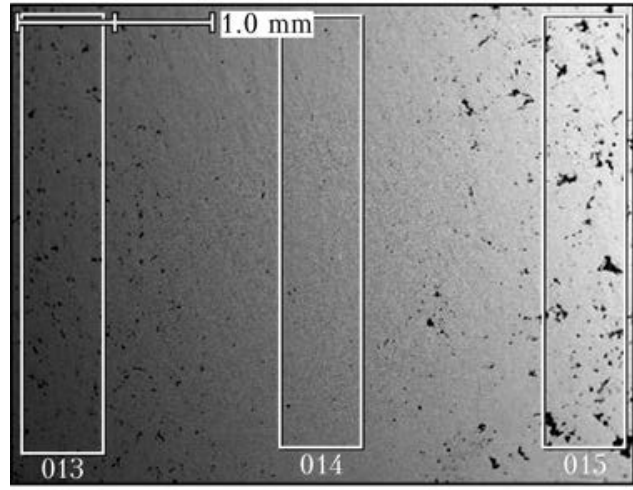

014

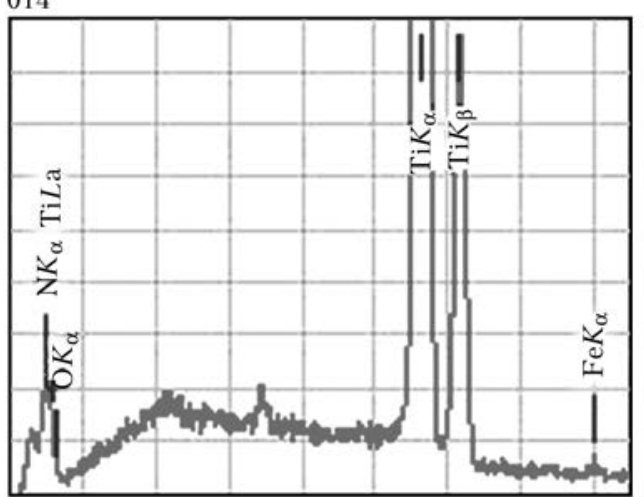

013

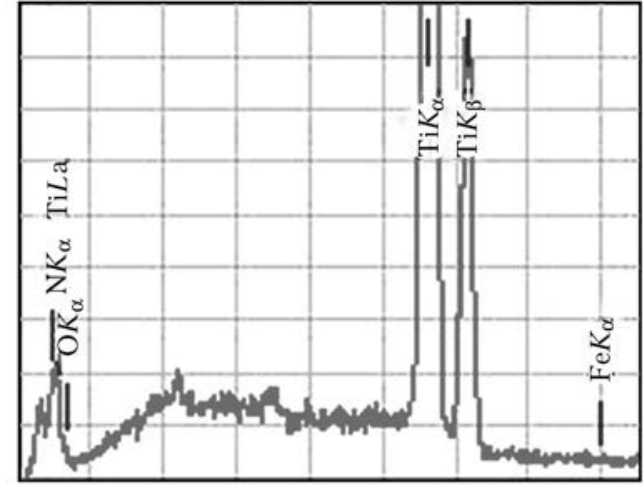

015

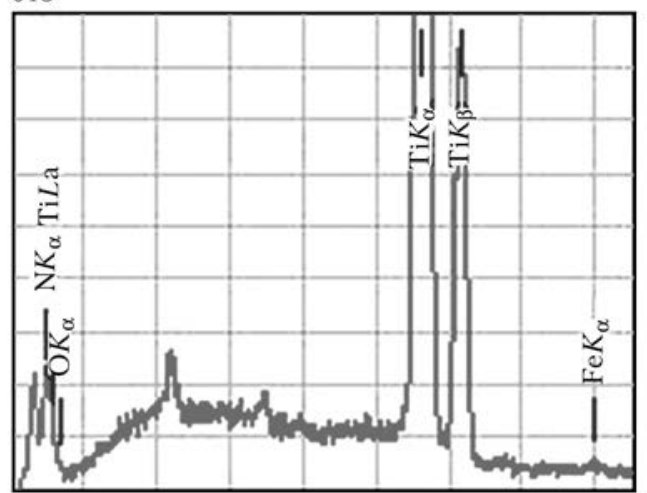

\begin{tabular}{|c|c|c|c|c|}
\hline Number of point & $\mathrm{Ti}$ & $\mathrm{N}$ & $\mathrm{O}$ & $\mathrm{Fe}$ \\
\hline 013 (base metal) & Base & 0.030 & 0.15 & 0.20 \\
\hline 014 (TMAZ) & Same & 0.013 & 0.18 & 0.25 \\
\hline 015 (base metal) & $\Rightarrow$ & 0.035 & 0.15 & 0.28 \\
\hline
\end{tabular}

Figure 5. Quantity distribution of elements in the VT1-0 titanium specimens

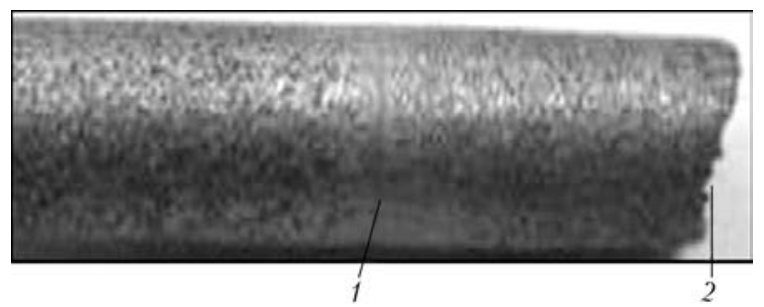

Figure 6. View of specimen after tension testing: 1 - weld; 2 - failure zone

\section{Conclusions}

1. Conventional friction welding of billets from VT1-0 sintered alloy was realized.

2. Technical possibility of application of conventional friction welding is shown for production of quality joints from sintered alloy in manufacture of long-length semi-products.

3 . The results of metallographic examination determined that width of weld made $0.08-0.25 \mathrm{~mm}$ and TMAZ width was $2-2.5 \mathrm{~mm}$. Pores were virtually absent in the weld, diameter of residual pores did not exceed $3 \mu \mathrm{m}$, that in TMAZ was up to 5 $\mu \mathrm{m}$, width of partially closed pores made not more than $3 \mu \mathrm{m}$, whereas maximum diameter of pores in the base metal lied in $70 \mu \mathrm{m}$ limit.

4. Dependencies of distribution of elements (nitrogen, oxygen, iron) in the weld were determined, and the fact is shown that welding with- out additional shielding does not promote auxiliary gas saturation.

5. Effect of structure on mechanical properties of welded joints from porous materials was determined. Relevance of application of conventional friction welding in production of fullstrength joint was grounded. Level of mechanical properties of welded joint from sintered titanium alloys was at the level of cast titanium VT1-0 and made $\sigma_{\mathrm{t}}=322-338 \mathrm{MPa}, \delta=7-9 \%$, and $\psi=14-18 \%$.

6 . The billets can be successfully remelted.

1. Ovchinnikov, A.V. (2014) On possibility to produce the rods from sintered titanium alloys using the welding methods. Avtomatich. Svarka, 1, 50-53.

2. Seliverstov, A.G., Tkachenko, Yu.M., Kulikovsky, R.A. et al. (2013) Effect of friction welding parameters on structure and mechanical properties of joints on titanium alloy VT3-1. The Paton Welding J., 1, 28-33.

3. Bolshakov, M.V., Chernitsyn, A.I. (1974) Structure and properties of titanium alloy OT4 and its friction welded joints. Svarochn. Proizvodstvo, 40-42.

4. Ovchinnikov, A.V. (2012) Application of titanium alloys with submicrocrystalline structure for reconditioning GTE rotor parts. The Paton Welding J., 2, 18-22.

5. Kovalenko, T.A., Ovchinnikov, A.V. (2010) Influence of initial structure on fracture mechanisms and mechanical properties of submicrocrystalline titanium. Novi Mater. $i$ Tekhnol. v Metallurgii ta Mashynobud., 1, 72-80. 